75 巻 756 号 $(2009-8)$

\title{
三重相反境界要素法による三次元弾塑性解析のための 初期応力定式化*
}

落合芳博*1

\section{Initial Stress Formulation for Three-Dimensional Elastoplastic Analysis by Triple-Reciprocity Boundary Element Method}

\author{
Yoshihiro OCHIAI*2 \\ *2 Department of Mechanical Engineering, Kinki University, \\ 3-4-1 Kowakae, Higashi-Osaka-shi, Osaka, 577-8502 Japan
}

\begin{abstract}
In general, internal cells are required to solve elastoplastic problems using a conventional boundary element method (BEM). However, in this case, the merit of BEM, which is ease of data preparation, is lost. Triple-reciprocity BEM can solve the two-dimensional elastoplasticity problems with a small plastic deformation. In this study, it is shown that three-dimensional elastoplastic problems can be solved without the use of internal cells, using the triple-reciprocity BEM. An initial stress formulation is adopted and the arbitrary distributions of the initial stress for elastoplastic analysis are interpolated using boundary integral equations and internal points. This interpolation corresponds to a thin plate spline. The fundamental solutions for this analysis are shown using polyharmonic function with volume distribution. The theory is expressed using a few fundamental solutions. In this method, strong singularities in the calculation of stresses at internal points become weak. A new computer program was developed and applied to solving several problems.
\end{abstract}

Key Words: Boundary Element Method, Elastoplasticity, Initial Stress, Computational Mechanics

\section{1. 緒言}

従来の境界要素法により三次元弾塑性解析を行う場 合，内部セルが必要になる，また，従来の境界要素法 では塑性状態の内部応力を計算する際, 強い特異性の 問題を考慮しなければならなかった，著者は二次元弾 塑性解析において，三重相反境界要素法によって，内 部セルを用いないで解析できることを示した(1)(2)，ま た，初期ひずみ法によって三次元弾塑性解析が可能で あることを示している(3). 二次元問題においては，初 期ひずみ法を初期応力法に変えることにより，平面ひ ずみ問題における付加項を考慮する必要がなくなっ た。また，有限要素法においては，初期ひずみ法より 初期応力法が一般的に良いとされている，本論文で は，初期応力定式化を用いて三次元弾塑性問題におい ても内部セルを用いないで解析が可能であることを示 す. 初期応力法に使用する高次基本解は，初期ひずみ 法で用いる高次基本解より多少短くなる利点がある が，他に初期応力定式化の利点があるかを調べる．補

* 原稿受付 2008 年 12 月 1 日。

*1 正員, 近畿大学理工学部機械工学科( - 577-8502 東大阪市 小若江 3-4-1)

E-mail : ochiai@mech.kindai.ac.jp
間には，体分布多重調和関数を使用した。なお，三重 相反境界要素法における高次基本解を誘導し，簡潔に まとめ上げることは非常に困難なことである.

\section{2. 理 論}

$2 \cdot 1$ 弾塑性解析 境界要素法を用いて任意の初 期応力 $\dot{\sigma}_{I j k}^{[1]}$ が作用すると考える初期応力法で弾塑性 解析を行うには, 次の境界積分方程式を解かなければ ならない(4)(5).

$$
\begin{aligned}
& c_{i j}(P) \dot{u}_{j}(P)=\int_{\Gamma}\left[u_{i j}^{[1]}(P, Q) \dot{p}_{j}(Q)\right. \\
& \left.\quad-p_{i j}(P, Q) \dot{u}_{j}(Q)\right] \mathrm{d} \Gamma+\int_{\Omega} \varepsilon_{j k i}^{[1]}(P, q) \dot{\sigma}_{I j k}^{[1]}(q) \mathrm{d} \Omega
\end{aligned}
$$

ただし，記号 $u_{j}$ 抢よび $p_{j}$ は変位扔よび表面力の $j$ 方 向成分であり， $\Gamma$ および $\Omega$ は境界および領域を示す。 $c_{i j}$ は滑らかな境界上では $0.5 \delta_{i j}$, 内点では $\delta_{i j}$ であ る. 2 点 $\mathrm{P}, \mathrm{Q}$ 間の距離を $r$ とすると, ケルビンの解 $u_{i j}^{[11}, p_{i j}$ は三次元の場合

$$
\begin{aligned}
u_{i j}^{[1]} & =\frac{1}{16 \pi(1-\nu) G r}\left[(3-4 \nu) \delta_{i j}+r_{, i} r_{, j}\right] \cdots( \\
p_{i j} & =\frac{-1}{8 \pi(1-\nu) G r^{2}}\left\{\left[(1-2 \nu) \delta_{i j}+3 r_{, i} r_{, j}\right] \frac{\partial r}{\partial n}\right. \\
& \left.-(1-2 \nu)\left(r_{, i} n_{j}-r_{, j} n_{i}\right)\right\} \cdots \cdots \cdots \cdots \cdots \cdots(
\end{aligned}
$$


で与えられる、ただし，ポアソン比をレ，横弾性係数 を $G$ とし, $n_{i}$ を単位法線ベクトルの $i$ 方向成分とす る. 式 (1)における関数 $\varepsilon_{j k i}^{[1]}$ は, 次式で与えられる.

$$
\begin{aligned}
\varepsilon_{j k i}^{[1]} & =\frac{-1}{16 \pi(1-\nu) G r^{2}}\left[(1-2 \nu)\left(\delta_{j i} r_{, k}+\delta_{k i} r_{, j}\right)\right. \\
& \left.-\delta_{j k} r_{, i}+3 r_{, i} r_{, j} r_{, k}\right] \quad \cdots \cdots \cdots \cdots \cdots \cdots \cdots \cdots \cdots \cdots \cdots \cdots \cdots \cdots \cdots \cdots \cdots
\end{aligned}
$$

式（1）には領域積分が含まれる。そこで，積分方程式 を用いた補間法を活用して領域積分を境界積分に変換 する。

$2 \cdot 2$ 初期応力分布の補間 三重相反法では，補 間が重要な事項である。三次元の場合，次式を用い $ろ^{(6)}$.

$$
\begin{aligned}
& \nabla^{2} \dot{\sigma}_{I j k}^{[1] S}=-\dot{\sigma}_{I j k}^{[2] S} \ldots \\
& \nabla^{2} \dot{\sigma}_{I j k}^{[2] S}=-\sum_{m=1}^{M} \dot{\sigma}_{I j k(m)}^{[3] P A}
\end{aligned}
$$

式 (5)，(6)は，次式のように書くことができる.

$$
\nabla^{4} \dot{\sigma}_{I j k}^{[1] S}=\sum_{m=1}^{M} \dot{\sigma}_{I j k(m)}^{[3 \mid P A}
$$

ただし，補間は初期応力 $\dot{\sigma}_{I j k}^{[1] s}(j, k=x, y, z)$ のそれ ぞれの成分に対して考えるものとする。

多重調和関数 $T^{[f]}$ は次の関係がある.

$$
\nabla^{2} T^{[f+1]}=T^{[f]}
$$

従って, $f$ 重調和関数 $T^{[f]}$ は次式で求めることがで きる。

$$
T^{[f+1]}=\int \frac{1}{r^{2}}\left(\int r^{2} T^{[f]} \mathrm{d} r\right) \mathrm{d} r
$$

三次元の場合の $f$ 重調和関数 $T^{[f]}$ およびその法線方 向微分係数は，一般に次式で与えられる。

$$
T^{[f]}=\frac{r^{2 f-3}}{4 \pi(2 f-2) !}
$$

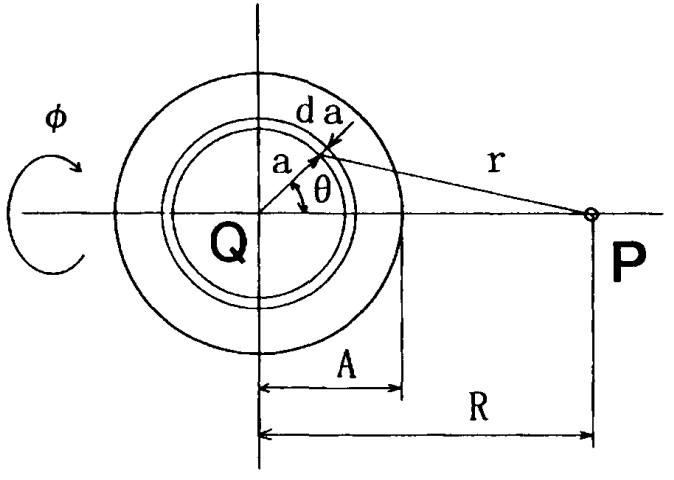

Fig. 1 Notation for polyharmonic function with volume distribution

$$
\frac{\partial T^{\mid f]}}{\partial n}=\frac{(2 f-3) r^{2 f-4}}{4 \pi(2 f-2) !} \frac{\partial r}{\partial n}
$$

重調和関数 $T^{(2)}$ は, $r$ の関数であり, $r=0$ で滑らか ではないので，二次元問題と同じ補間では滑らかな補 間が得られない。

式(6)の $\dot{\sigma}_{I j k}^{[3] P A}$ は， $\dot{\sigma}_{I j k}^{[3] P}$ を半径 $A$ の領域に一様 に分布させた状態を示す．定式化のために，図 1 に示 すように半径 $A$ の領域に一様に分布させた状態を示 す. 次式で定義される体分布多重調和関数 $T^{|f| A}$ を導 入する。

$$
T^{[f] A}=\int_{0}^{A}\left\{\int_{0}^{2 \pi}\left[\int_{0}^{\pi} T^{[f]} a^{2} \sin \theta \mathrm{d} \theta\right] \mathrm{d} \phi\right\} \mathrm{d} a
$$

ただし， $r^{2}=R^{2}+a^{2}-2 a R \cos \theta$ である。式(12)の積 分を行うと $R$ の関数となるが, 式(10), (11)との整合 性のために $R$ を $r$ 書き改めて, 体分布多重調程関 数 $T^{[f] A}$ を以下に示す.

$$
\begin{array}{ll}
T^{|f| A}=\frac{1}{2 r(2 f+1) !}\left[(2 f A-r)(r+A)^{2 f}+(2 f A+r)(r-A)^{2 f}\right], & r>A \\
T^{|f| A}=\frac{1}{2 r(2 f+1) !}\left[(2 f A-r)(A+r)^{2 f}-(2 f A+r)(A-r)^{2 f}\right], & r \leq A
\end{array}
$$

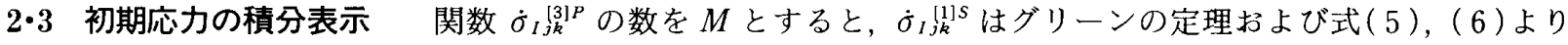
次式で与えられる。

$$
\begin{aligned}
& c \dot{\sigma}_{I j k}^{[1] S}(P)=-\sum_{f=1}^{2}(-1)^{f} \int_{\Gamma}\left[T^{[f]}(P, Q) \frac{\partial \dot{\sigma}_{I j k}^{[f] S}(Q)}{\partial n}-\frac{\partial T^{[f]}(P, Q)}{\partial n} \dot{\sigma}_{I j k}^{[f] S}(Q)\right] \mathrm{d} \Gamma \\
& -\sum_{m=1}^{M} T^{[2] A}(P, q) \dot{\sigma}_{l j k(m)}^{[3] P A}(q)
\end{aligned}
$$

式 ( 6 )より $\dot{\sigma}_{I j k}^{[2] S}$ は同様に次式で与えられる。

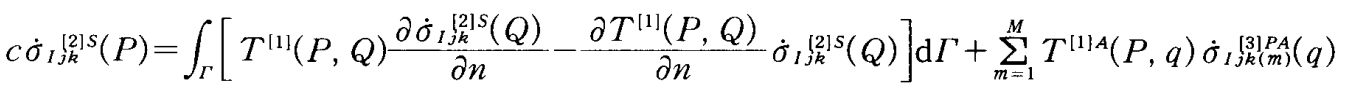

$2 \cdot 4$ 三重相反法 関数 $\varepsilon_{j k i}^{[1]}$ に対して次式を満足する関数 $\varepsilon_{j k i}^{[f]}$ が存在すると仮定する.

$$
\nabla^{2} \varepsilon_{j k i}^{[j+1]}=\varepsilon_{j k i}^{[f]}
$$

式(17)およびグリーンの定理より，式（1）は次式になる.

$$
c_{i j}(P) \dot{u}_{j}(P)=\int_{\Gamma}\left[u_{i j}^{[1]}(P, Q) \dot{p}_{j}(Q)-p_{i j}(P, Q) \dot{u}_{j}(Q)\right] \mathrm{d} \Gamma-\sum_{f=1}^{2}(-1)^{f} \int_{\Gamma}\left[\frac{\partial \varepsilon_{j k i}^{[f+1]}(P, Q)}{\partial n} \dot{\sigma}_{I j k}^{[f] s}(Q)\right.
$$




$$
\left.-\varepsilon_{j k i}^{\mid f+1]}(P, Q) \frac{\partial \dot{\sigma}_{I j k}^{[f] S}(Q)}{\partial n}\right] \mathrm{d} \Gamma+\sum_{m=1}^{M} \varepsilon_{j k i}^{[3] A}(P, q) \dot{\sigma}_{I j k(m)}^{[3] P A}(q)
$$

高次のケルビンの解 $u_{i j}^{[f]}$ は次式で得られる(1)(2).

$$
u_{i, j}^{[f]}=\frac{-1}{2(1-\nu) G} T_{, i j}^{[f+1]}+\frac{\delta_{i j} T_{, k k}^{[f+1]}}{G}
$$

同様に，体分布多重調和関数を用いた高次のケルビンの解 $u_{i j}^{[f] A}$ は次式で得られる.

$$
u_{i j}^{[f] A}=\frac{-1}{2(1-\nu) G} T_{, i j}^{[f+1] A}+\frac{\delta_{i j} T_{, k}^{[f+1] A}}{G}
$$

式(20)に式(10)を代入すると, 関数 $u_{i j}^{[f]}$ が得られる.

$$
u_{i j}^{[f]}=\frac{(2 f-1) r^{2 f-3}}{8 \pi(1-\nu) G(2 f) !}\left[(4 f-1-4 f \nu) \delta_{i j}-(2 f-3) r_{, i} r_{, j}\right]
$$

本論文では実際の計算に扔いて $\varepsilon_{i j k}^{[1]}$ は用いない。計算に必要な $\varepsilon_{i j k}^{[f]}, \partial \varepsilon_{i j k}^{[f]} / \partial n, \varepsilon_{i j k}^{[3] A}$ を示す。

$$
\begin{aligned}
& \varepsilon_{i j k}^{\mid f j]}=\frac{(2 f-1)(2 f-3) r^{2 f-4}}{8 \pi(1-\nu)(2 f) ! G}\left[(2 f-1-2 f \nu)\left(\delta_{j k} r_{, i}+\delta_{i k} r_{, j}\right)-\delta_{i j} r_{, k}-(2 f-5) r_{, i} r_{, j} r_{, k}\right] \cdots \cdots \cdots \cdots \cdots \cdots \cdots(22) \\
& \frac{\partial \varepsilon_{i j k}^{[f]}}{\partial n}=\frac{(2 f-1)(2 f-3) r^{2 f-5}}{8 \pi(1-\nu)(2 f) ! G}\left\{(2 f-5)\left[(2 f-1-2 f \nu)\left(\delta_{j k} r_{, i}+\delta_{i k} r_{, j}\right)-\delta_{i j} r_{, k}-(2 f-7) r_{, i} r_{, j} r_{, k}\right] \frac{\partial r}{\partial n}\right. \\
& \left.\quad-(2 f-5)\left(r_{, j} r_{, k} n_{i}+r_{, i} r_{, k} n_{j}+r_{, i} r_{, j} n_{k}\right)+(2 f-1-2 f \nu)\left(\delta_{j k} n_{i}+\delta_{i k} n_{j}\right)-\delta_{i j} n_{k}\right\} \cdots \cdots \cdots \cdots \cdots \cdots \cdots \cdots \cdots(23) \\
& \varepsilon_{i j k}^{[3] A}=\frac{A^{3}}{30240(1-\nu) r^{4} G}\left[-\left(\delta_{j k} r_{, i}+\delta_{i k} r_{, j}+\delta_{i j} r_{, k}\right)\left(105 r^{6}+63 A^{2} r^{4}-9 A^{4} r^{2}+A^{6}\right)\right. \\
& \left.\quad-r_{, i} r_{, j} r_{, k}\left(105 r^{6}-63 A^{2} r^{4}+27 A^{4} r^{2}-5 A^{6}\right)+18(1-\nu)\left(\delta_{j k} r_{, i}+\delta_{i k} r_{, j}\right) r^{2}\left(35 r^{4}+14 A^{2} r^{2}-A^{4}\right)\right], \quad r>A
\end{aligned}
$$

$$
\begin{aligned}
& \varepsilon_{i j k}^{[3] A}=\frac{r}{15120(1-\nu) G}\left[-\left(\delta_{j k} r_{, i}+\delta_{i k} r_{, j}+\delta_{i j} r_{, k}\right)\left(-r^{4}+18 A^{2} r^{2}+63 A^{4}\right)+4 r_{, i} r_{, j} r_{, k} r^{2}\left(-r^{2}+9 A^{2}\right)\right. \\
& \left.\quad+9(1-\nu)\left(\delta_{j k} r_{, i}+\delta_{i k} r_{, j}\right)\left(-r^{4}+14 A^{2} r^{2}+35 A^{4}\right)\right], \quad r \leq A \quad \ldots \ldots \ldots \ldots \ldots \ldots \ldots \ldots \ldots \ldots \ldots \ldots \ldots \ldots \ldots \ldots \ldots \ldots \ldots \ldots \ldots \ldots \ldots \ldots \ldots \ldots \ldots \ldots \ldots \ldots \ldots \ldots \ldots \ldots \ldots
\end{aligned}
$$

以上の式は, 式(17) を満足している.

$2 \cdot 5$ 内部応力 次に, 関数 $\sigma_{j k i}^{[f]}$ は, 次の変位と応力の関係式より得られる.

$$
\sigma_{i j}=\frac{2(1-\nu) G}{(1-2 \nu)} \delta_{i j} u_{k, k}+G\left(u_{i, j}+u_{j, i}\right)
$$

従来の境界要素法では, 次式で内部応力を求めていた。

$$
\dot{\sigma}_{i j}(p)=\int_{\Gamma}\left[-\sigma_{k i j}^{[1]}(p, Q) \dot{p}_{k}(Q)-S_{k i j}(p, Q) \dot{u}_{k}(Q)\right] \mathrm{d} \Gamma+\int_{\Omega} \varepsilon_{i j k l}^{[1]}(p, q) \dot{\sigma}_{I}[k](q) \mathrm{d} \Omega-\dot{\sigma}_{I i j}^{[1]}(q)
$$
ただし，

$$
\begin{aligned}
& S_{k i j}=\frac{G}{4 \pi(1-\nu) r^{3}}\left\{3\left[(1-2 \nu) \delta_{i j} r_{, k}+\nu\left(\delta_{i k} r_{, j}+\delta_{j k} r_{, i}\right)-5 r_{, i} r_{, j} r_{, k}\right] \frac{\partial r}{\partial n}+3 \nu\left(n_{i} r_{, j} r_{, k}+n_{j} r_{, i} r_{, k}\right)\right. \\
& \left.+(1-2 \nu)\left(3 n_{k} r_{, i} r_{, j}+n_{j} \delta_{i k}+n_{i} \delta_{j k}\right)-(1-4 \nu) n_{k} \delta_{i j}\right\}
\end{aligned}
$$

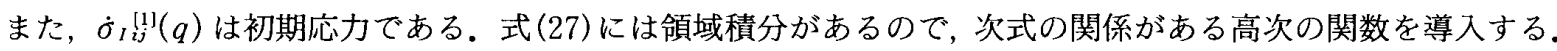

$\nabla^{2} \varepsilon_{i j k l}^{[f+1]}=\varepsilon_{i j k l}^{[f]}$

式(5)，(6)，(29)および，グリーンの恒等式より式(27)は，次式になる.

$$
\begin{gathered}
\dot{\sigma}_{i j}(p)=\int_{\Gamma}\left[-\sigma_{k i j}^{[1]}(p, Q) \dot{p}_{k}(Q)-S_{k i j}(p, Q) \dot{u}_{k}(Q)\right] \mathrm{d} \Gamma-\sum_{f=1}^{2}(-1)^{f} \int_{\Gamma}\left[\frac{\partial \sigma_{i j k l}^{[f+1]}(p, Q)}{\partial n} \dot{\varepsilon}_{I k l}^{[f] S}(Q)\right. \\
\left.\quad-\sigma_{i j k l}^{[f+1]}(p, Q) \frac{\partial \dot{\varepsilon}_{l k l}^{[f] S}(Q)}{\partial n}\right] \mathrm{d} \Gamma+\sum_{m=1}^{M} \varepsilon_{i j k l}^{[3] A}(p, q) \dot{\sigma}_{I k l(m)}^{[3] P A}(q)-\dot{\sigma}_{I i j}^{[1]}(q) \ldots \ldots \ldots \ldots \ldots \ldots \ldots \ldots \ldots \ldots \ldots \ldots \ldots \ldots \ldots \ldots \ldots \ldots \ldots \ldots \ldots
\end{gathered}
$$

ただし，関数 $\varepsilon_{i j k l,}^{[f]} \partial \varepsilon_{i j k l}^{[f]} / \partial n, \varepsilon_{i j k l}^{[3] A}$ は次式である.

$$
\begin{aligned}
& \varepsilon_{i j k l}^{[f]}=\frac{(2 f-1)(2 f-3) r^{2 f-5}}{4 \pi(1-\nu)(2 f) !}\left\{(2 f-1-2 f \nu)\left(\delta_{i k} \delta_{j l}+\delta_{i l} \delta_{j k}\right)+(2 f-5)(f-1-f \nu)\left(\delta_{j l} r_{, i} r_{, k}+\delta_{j k} r_{, i} r_{, l}+\delta_{i l} r_{, j} r_{, k}\right.\right. \\
& \left.\left.\quad+\delta_{i k} r_{, j} r_{, l}\right)-(1-2 f \nu)\left[(2 f-5) \delta_{k l} r_{, i} r_{, j}+\delta_{i j} \delta_{k l}\right]+(2 f-5) \delta_{i j} r_{, k} r_{, l}-(2 f-5)(2 f-7) r_{, i} r_{, j} r_{, k} r_{, l}\right\} \cdots \cdots(31) \\
& \frac{\partial \varepsilon_{i j k l}^{[f]}}{\partial n}=\frac{(2 f-1)(2 f-3)(2 f-5) r^{2 f-6}}{2 \pi(1-\nu)(2 f) !}\left[\left\{(2 f-1-2 f \nu)\left(\delta_{i k} \delta_{j l}+\delta_{i l} \delta_{j k}\right)\right.\right. \\
& \quad+(2 f-7)(f-1-f \nu)\left(\delta_{j l} r_{, i} r_{, k}+\delta_{j k} r_{, i} r_{, l}+\delta_{i l} r_{, j} r_{, k}+\delta_{i k} r_{, j} r_{, l}\right) \\
& \left.\quad-(1-2 f \nu)\left[(2 f-7)\left(\delta_{k l} r_{, i} r_{, j}+\delta_{i j} r_{, k} r_{, l}\right)+\delta_{i j} \delta_{k l}\right]-(2 f-7)(2 f-9) r_{, i} r_{, j} r_{, k} r_{, l}\right\} \frac{\partial r}{\partial n}+(f-1-f \nu)
\end{aligned}
$$




$$
\begin{aligned}
& \times\left[\left(\delta_{j l} n_{k}+\delta_{j k} n_{l}\right) r_{, i}+\left(\delta_{i i} n_{k}+\delta_{i k} n_{l}\right) r_{, j}+\left(\delta_{j l} n_{i}+\delta_{i i} n_{j}\right) r_{, k}+\left(\delta_{j k} n_{i}+\delta_{i k} n_{j}\right) r_{, l}\right]-(1-2 f \nu) \\
& \left.\times\left[\delta_{i j}\left(r_{, l} n_{k}+r_{, k} n_{l}\right)+\delta_{k l}\left(r_{, j} n_{i}+r_{, i} n_{j}\right)\right]-(2 f-7)\left[\left(r_{, l} n_{k}+r_{, k} n_{l}\right) r_{, i} r_{, j}+\left(r_{, j} n_{i}+r_{, i} n_{j}\right) r_{, k} r_{, l}\right]\right] \cdots \\
& \varepsilon_{i j k l}^{[3 \mid A}=\frac{A^{3}}{15120(1-\nu) r^{5}}\left\{18 \nu r^{2} \delta_{i j}\left[\delta_{k l}\left(35 r^{4}+14 A^{2} r^{2}-A^{4}\right)+r_{, k} r_{, l}\left(35 r^{4}-14 A^{2} r^{2}+3 A^{4}\right)\right]\right. \\
& -\left(\delta_{i j} \delta_{k l}+\delta_{k j} \delta_{l i}+\delta_{k i} \delta_{l j}\right)\left(105 r^{6}+63 A^{2} r^{4}-9 A^{4} r^{2}+A^{6}\right)-\left(\delta_{i j} r_{, k} r_{, l}+\delta_{k j} r_{, i} r_{, l}+\delta_{k i} r_{, j} r_{, l}\right. \\
& \left.+\delta_{k l} r_{, i} r_{, j}+\delta_{i l} r_{, k} r_{, j}+\delta_{j l} r_{, k} r_{, i}\right)\left(105 r^{6}-63 A^{2} r^{4}+27 A^{4} r^{2}-5 A^{6}\right)-r_{, j} r_{, i} r_{, k} r_{, l} \\
& \times\left(-105 r^{6}+189 A^{2} r^{4}-135 A^{4} r^{2}+35 A^{6}\right)+9(1-\nu) r^{2}\left[2\left(\delta_{k i} \delta_{j l}+\delta_{k j} \delta_{i l}\right)\left(35 r^{4}+14 A^{2} r^{2}-A^{4}\right)\right. \\
& \left.\left.+\left(\delta_{k i} r_{, j} r_{l}+\delta_{k j} r_{, i} r_{l}+\delta_{l i} r_{, j} r_{, k}+\delta_{l j} r_{, i} r_{, k}\right)\left(35 r^{4}-14 A^{2} r^{2}+3 A^{4}\right)\right]\right\}, \quad r>A \\
& \varepsilon_{i j k l}^{(3) A}=\frac{1}{7560(1-\nu)}\left\{9 \nu \delta_{i j}\left[\delta_{k l}\left(-r^{4}+14 A^{2} r^{2}+35 A^{4}\right)+4 r_{, k} r_{, l} r^{2}\left(-r^{2}+7 A^{2}\right)\right]\right. \\
& -\left(\delta_{i j} \delta_{k l}+\delta_{i k} \delta_{j l}+\delta_{i l} \delta_{j k}\right)\left(-r^{4}+18 A^{2} r^{2}+63 A^{4}\right)-4\left(\delta_{k l} r_{, i} r_{, j}+\delta_{j l} r_{, i} r_{, k}+\delta_{j k} r_{, i} r_{, l}+\delta_{i l} r_{, j} r_{, k}\right. \\
& \left.+\delta_{i k} r_{, j} r_{, l}+\delta_{i j} r_{, k} r_{, l}\right) r^{2}\left(-r^{2}+9 A^{2}\right)+8 r_{, i} r_{, j} r_{, k} r_{, l} r^{4}+9(1-\nu)\left[\left(\delta_{i k} \delta_{j l}+\delta_{i l} \delta_{j k}\right)\left(-r^{4}+14 A^{2} r^{2}+35 A^{4}\right)\right. \\
& \left.\left.+2\left(\delta_{j l} r_{, i} r_{, k}+\delta_{j k} r_{, i} r_{, l}+\delta_{i l} r_{, j} r_{, k}+\delta_{i k} r_{, j} r_{, l}\right) r^{2}\left(-r^{2}+7 A^{2}\right)\right]\right\}, \quad r \leq A
\end{aligned}
$$

以上の式は, 式(29)を満足している.

$2 \cdot 6$ 加工硬化 繰り返し計算により弾塑性解析 を行う。まず，塑性が開始する荷重 $P_{S}$ を求め, 最終 荷重を $P_{o}$, 時間分割数を $N$ とし, $\left(P_{o}-P_{S}\right) / N$ の荷重 を順次加えて行く．時間ステップ $k$ における降伏応 力を $\sigma_{o}^{k}$, 相当塑性ひずみ増分を $\mathrm{d} \varepsilon_{e}^{P}$ とし, 加工硬化係 数を $H$ とすると, 時間ステップ $k+1$ における降伏応 力 $\sigma_{0}^{k+1}$ は次式で与えられる.

$$
\sigma_{o}^{k+1}=\sigma_{o}^{k}+H \mathrm{~d} \varepsilon_{e}^{P}
$$

ミーゼスの降伏条件を用いる場合, 応力速度より, 偏 差応力 $S_{i j}$ を求め, 次式により相当応力 $\sigma_{e}$ を計算す る。

$$
\sigma_{e}=\sqrt{\frac{3}{2} S_{i j} S_{i j}}
$$

ミーゼスの降伏条件は次式で示される。

$$
\sigma_{e}-\sigma_{o}=0
$$

塑性ひずみ増分 $\mathrm{d} \varepsilon_{i j}^{P}$ を決定するには，次の PrandtlReuss の式を用いる.

$$
d \varepsilon_{i j}^{P}=S_{i j} d \lambda \cdots
$$

ただし， $d \lambda$ は比例係数である，以上の式より，仮の塑 性ひずみ増分 $\mathrm{d} \varepsilon_{i j}^{P}$ を計算し, 応力ーひずみ関係式より 仮の初期応力速度増分を計算する．境界上の点および 内点の仮の初期応力速度を用いて式(15)，(16)により 仮の初期応力速度分布を補間し, 式(18)より変位速度 および表面力速度を求め,さらに応力速度を求める。 再び, 初期応力速度增分を計算する操作を繰り返し, 初期応力速度分布増分を収束させる. その後, 次の時 間ステップの塑性計算を行う.

\section{3. 解 析 例}

図 2(a ) に示す内圧 $P=1200 \mathrm{MPa}$ を受ける円筒の 弾塑性解析を行なった。内径 $a=20 \mathrm{~mm}$, 外径 $b=60$ $\mathrm{mm}$ とし, 縦弾性係数 $E=210 \mathrm{GPa}$, ポアソン比 $\nu=$
0.3 とし, 降伏応力を $Y=1200 \mathrm{MPa}$ とする. 加工硬 化係数 $H=0.1 E$ とし, 一定要素を用い, 要素数 680 , 内点数 315 で計算を行った. 上下方向の変位は拘束さ れていないものとしており，図2(b)には計算に使用 した内点を示す. 計算は初期応力法と初期ひずみ法 ${ }^{(3)}$ で行い, 図 3 に有限要素法(ANSYS)による解との比 較を示した(7). RMS (二乗平均平方根) は, 初期応力法

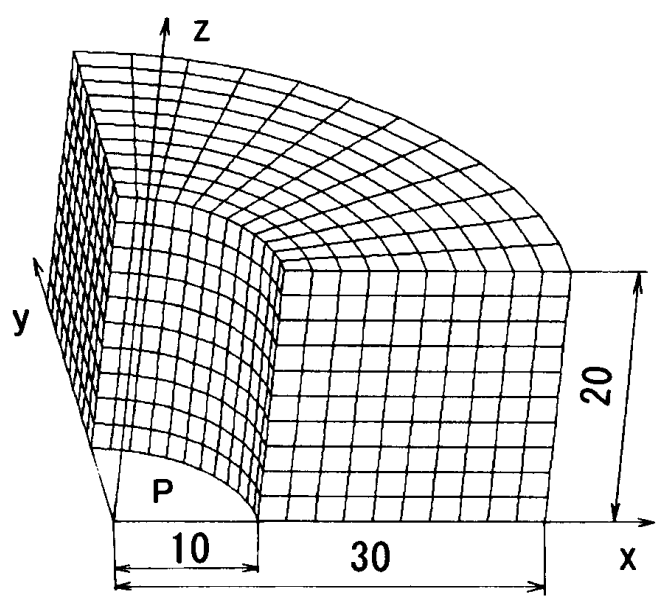

(a) Boundary elements

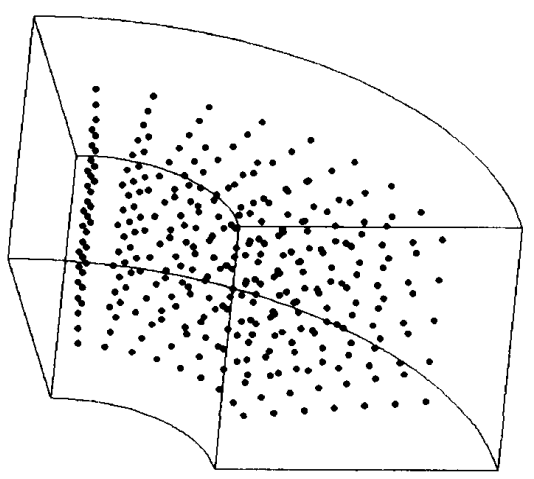

(b) Internal points

Fig. 2 Hollow cylinder with internal pressure 
と有限要素法では 30.6 であり, 初期ひずみ法と有限 要素法では 37.4 であったので, あまり有意差はなか った。また，計算条件を合わせるとCPU Timeの差 も 2 パーセント以内であった.

次に, 図 4 に示す切り欠きを有する長方形板の問題 を解析した(8).ただし, 縦弾性係数 $E=70 \mathrm{GPa}$ ，ポア ソン比 $\nu=0.2$ とし, 降伏応力を $Y=243 \mathrm{MPa}$ とし た。板の厚さを $6 \mathrm{~mm}$ とし, 対称性より 4 分の 1 の領 域で解析を行った。図 $5(\mathrm{a}),(\mathrm{b})$ に要素分割と補間 のための内点を示す. 要素数 856, 内点数 715 で計算 を行った。図 6 は，塑性の拡がりを示す。

次に, 図 7 に示す円孔を有する長方形板の問題を解 析した ${ }^{(9)}$.ただし, 縰弾性係数 $E=70 \mathrm{GPa}$, ポアソン 比 $\nu=0.2$ とし, 降伏応力を $Y=243 \mathrm{MPa}$ とした。板 の厚さを $6 \mathrm{~mm}$ とし，対称性より 4 分の 1 の領域で解

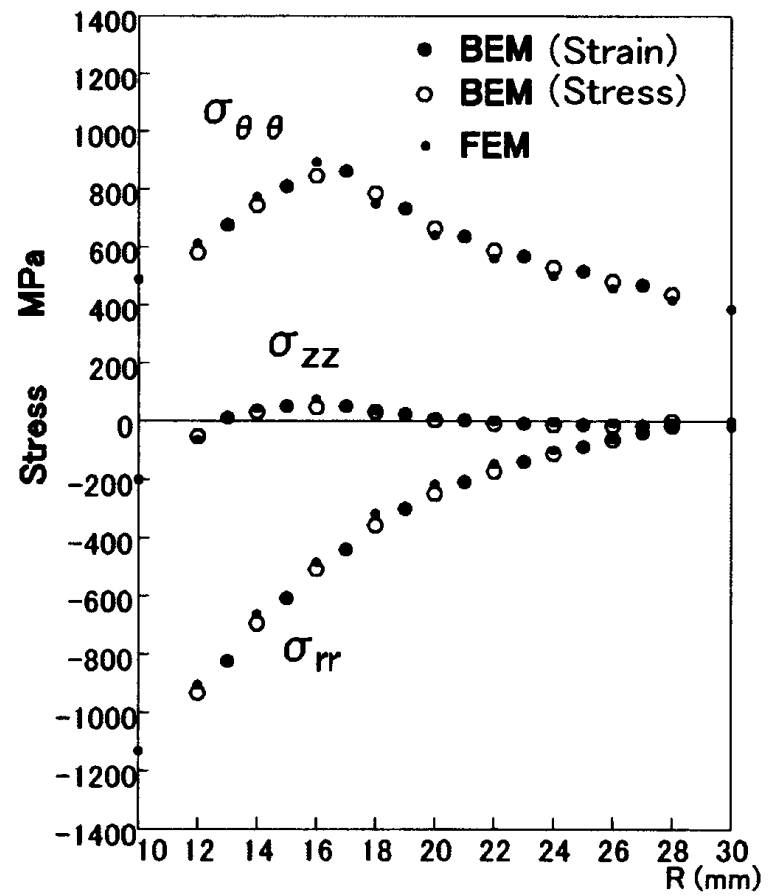

Fig. 3 Stress distribution in hollow cylinder (initial stress and strain methods)

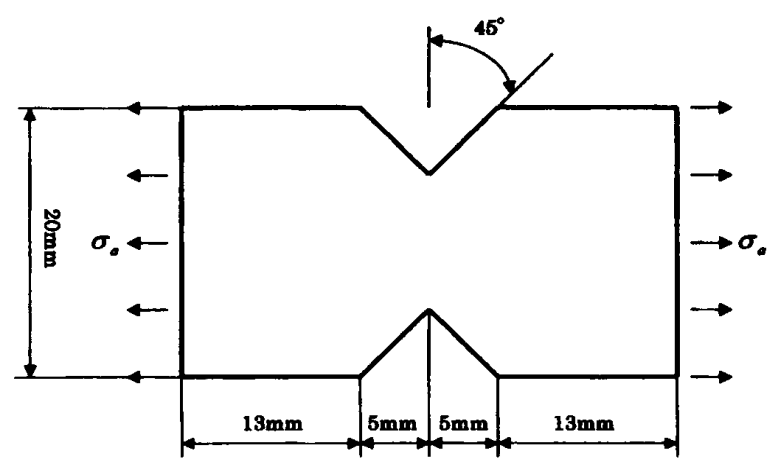

Fig. 4 Notched tensile specimen
析を行った。図 8(a)，(b)に要素分割と補間のため の内点を示す. 要素数 856 , 内点数 660 で計算を行っ た。図 9 は，塑性の拡がりを示す。

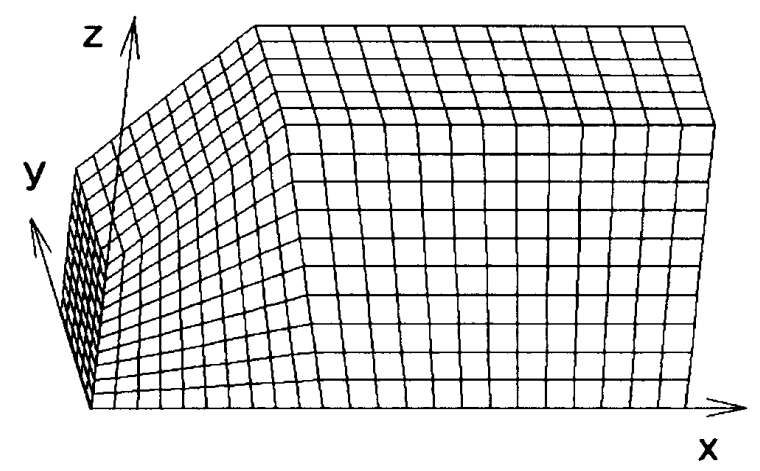

(a) Boundary elements

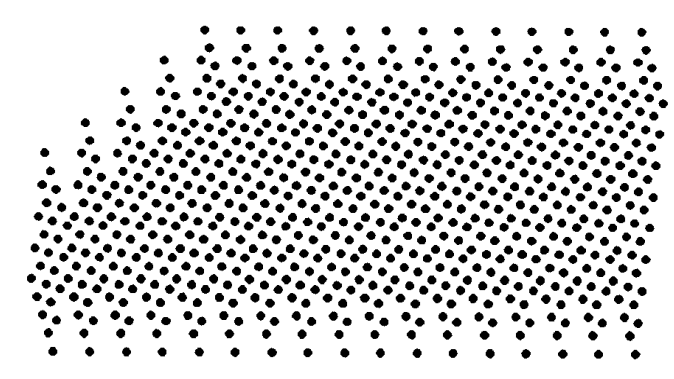

(b) Internal points

Fig. 5 Notched tensile specimen

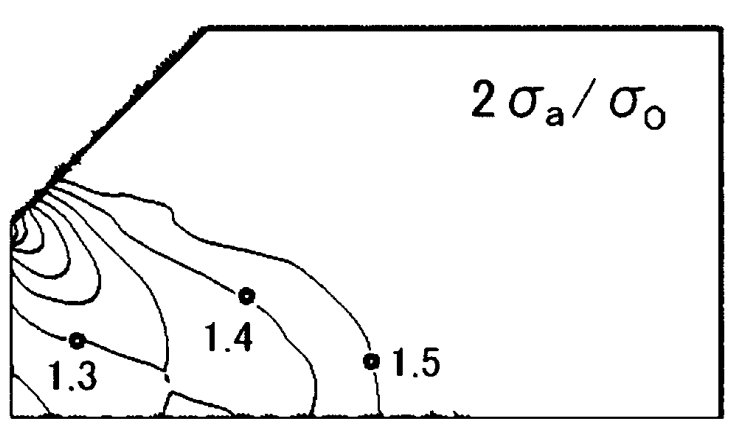

Fig. 6 Plastic zone obtained for various values of $2 \sigma_{a} / \sigma_{o}$

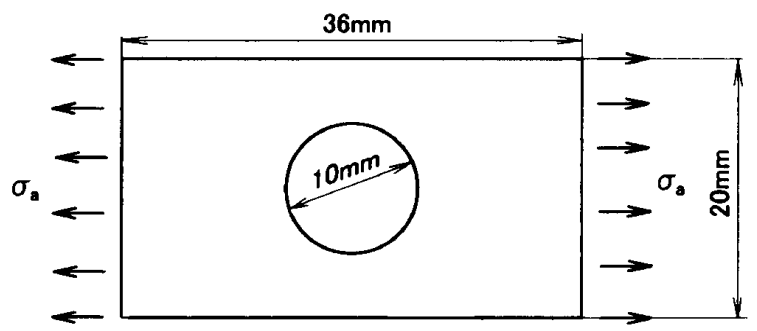

Fig. 7 Perforated tension strip 


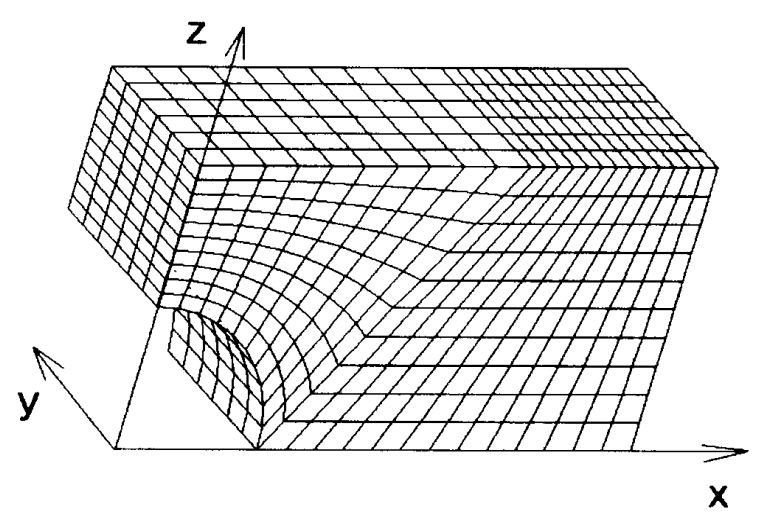

(a) Boundary elements

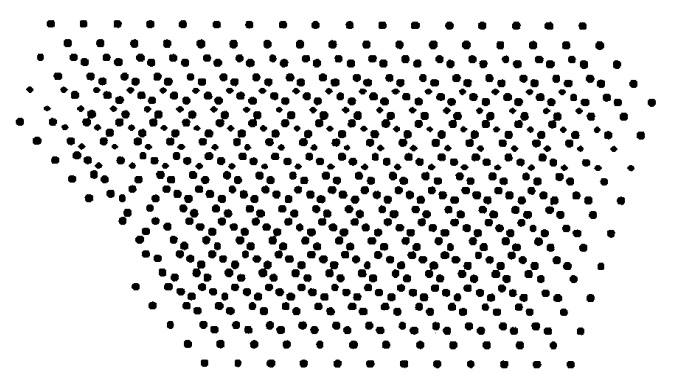

(b) Internal points

Fig. 8 Boundary element in quarter region

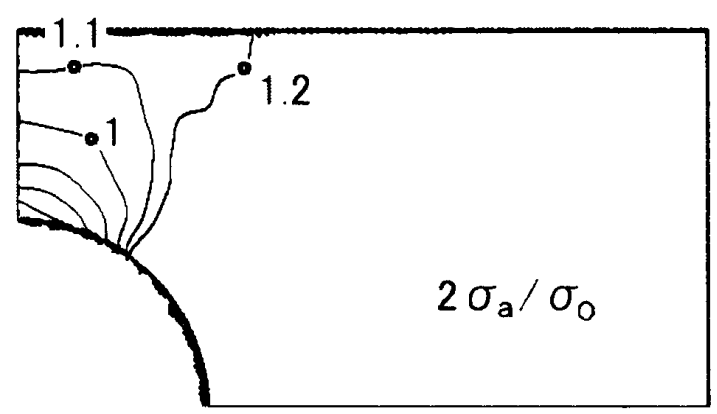

Fig. 9 Plastic zone obtained for various values of $2 \sigma_{a} / \sigma_{0}$

\section{4. 結 言}

三次元弾塑性問題を従来の境界要素法で解析するに は内部セルが必要であった。内部セルが不要な三重相
反境界要素法に必要な初期応力定式化のための高次基 本解を示した。三重相反境界要素法を用いることによ り，内部セルを用いないで三次元弾塑性解析が可能な ことがわかった。これにより，データの入力が容易で ある境界要素法の利点が, 維持できることが示され た。また，内部応力の計算時の特異性が弱いため, 計 算が容易になった，有限要素法の場合，初期ひずみ法 より初期応力法のほうが一般的に良いとされている が, 三重相反境界要素法では, 高次基本解が少し短く なるだけで, 計算精度やCPU Time はほとんど差異 がなかった。

\section{文献}

(1) Ochiai, Y. and Kobayashi, T., Initial Stress Formulation for Elastoplastic Analysis by Improved MultipleReciprocity Boundary Element Method, Engineering Analysis with Boundary Elements, Vol. 23 (1999), pp. 167-173.

(2) Ochiai, Y. and Kobayashi, T., Initial Strain Formula tion without Internal Cells for Elastoplastic Analysis by Triple-Reciprocity BEM, International Journal for Numerical Methods in Engineering, Vol. 50 (2001), pp. 1877-1892.

(3) Ochiai, Y., Three-Dimensional Elastoplastic Analysis by Triple-Reciprocity Boundary-Element Method, Communication in Numerical Methods in Engineering Vol. 23, No. 8 (2007), pp. 721-732.

(4) Telles, J. C. F., The Boundary Element Method Applied to Inelastic Problems, (1983), Springer-Verlag, Berlin.

(5) Brebbia, C. A., Telles, J.C.F. and Wrobel, L. C., Boundary Element Techniques-Theory and Applica. tions in Engineering, (1984), pp. 252-266, Springer Verlag, Berlin.

(6) Ochiai, Y. and Sladek, V., Numerical Treatment of Domain Integrals without Internal Cells in ThreeDimensional BIEM Formulations, CMES (Computer Modeling in Engineering \& Sciences), Vol.6, No.6 (2004), pp. 525-536.

(7) Nakasone, Y., Yoshimoto, S. and Stolarski, T. A., Engineering Analysis with ANSYS Software, (2007), Butterworth-Heinemann.

(8) Nayak, G.C. and Zienkiewicz, O.C., International Journal for Numerical Methods in Engineering, Vol. 5 (1972), p. 113.

(9) Zienkiewicz, O.C. and Tayor, R. L., The Finite Ele ment Method, Vol. 2, 4th ed., (1991), pp. 244-250, McGraw-Hill, New York. 